\title{
Biomarkers for cancer cachexia: is there also a genetic component to cachexia?
}

\author{
B. H. L. Tan • D. A. C. Deans • R. J. E. Skipworth • \\ J. A. Ross • K. C. H. Fearon
}

Published online: 22 February 2008

(C) Springer-Verlag 2008

\section{Erratum to: Support Care Cancer}

\section{DOI 10.1007/s00520-007-0367-z}

The footnote relating to presentation of the data at the MASCC/ISOO 20th Anniversary International Symposium was missing from the original publication.

The online version of this article can be found at http://dx.doi.org/ 10.1007/s00520-007-0367-z.

Presented as an invited lecture at the MASCC/ISOO 20th Anniversary International Symposium Supportive Care in Cancer in St Gallen, June 2007.

B. H. L. Tan $(\bowtie) \cdot$ D. A. C. Deans · R. J. E. Skipworth •

J. A. Ross $\cdot$ K. C. H. Fearon

Clinical and Surgical Sciences (Surgery),

School of Clinical Sciences and Community Health,

The University of Edinburgh,

Royal Infirmary, 51 Little France Crescent,

Edinburgh EH15 4SA, UK

e-mail: benjamin.tan@ed.ac.uk 